\title{
Microbiological study of dacryocystitis in northwest of Iran
}

This article was published in the following Dove Press journal: Clinical Ophthalmology

\author{
Fatemeh Eslami' \\ Hamid Reza Ghasemi Basir ${ }^{2}$ \\ Abbas Moradi ${ }^{3}$ \\ Shokoufe Heidari Farah ${ }^{3}$ \\ 'Department of Ophthalmology, \\ ${ }^{2}$ Department of Pathology, ${ }^{3}$ School \\ of Medicine, Hamadan University of \\ Medical Sciences, Hamadan, Iran
}

\begin{abstract}
Background: The prevalence of bacterial pathogens isolated from patients with acute and chronic dacryocystitis and the pattern of antibiotic susceptibility tests are varied in each region. Moreover, the management of dacryocystitis is only based on clinical observations without microbiological evaluation. The present study aimed to identify epidemiologic and etiologic factors of dacryocystitis in our geographical area.
\end{abstract}

Materials and methods: This cross-sectional and analytical study was carried out in the ophthalmology department of Hamadan University of Medical Sciences (northwest of Iran) during 2016-2017. Nasolacrimal duct discharges were inoculated to culture media including blood agar, eosin methylene blue, chocolate agar, and Sabouraud agar for the determination of microbial agents. Disc diffusion method with MAST antibiogram discs was used for antibiotic susceptibility tests, according to the Clinical and Laboratory Standards Institute, 2017.

Results: Of the total 129 patients enrolled in the study, $34.1 \%$ had acute dacryocystitis and $65.9 \%$ showed chronic type. The result of culture was positive in $75.2 \%$ of patients. Staphylococcus aureus, Staphylococcus epidermidis, Streptococcus pneumoniae, Pseudomonas spp., and Candida albicans were the most prevalent microorganisms. The most sensitive antibiotics used against prevalent bacteria were ciprofloxacin $(75.9 \%)$, ceftriaxone (73.6\%), vancomycin (67.8\%), and chloramphenicol (60.9\%), respectively.

Conclusion: The present study is useful for determining the appropriate antibiotic for systemic treatment of dacryocystitis in our region. Ciprofloxacin and vancomycin are the most sensitive antibiotics against the most common isolated microorganisms in both age groups (under and above 10 years) that can be used for empirical therapy of dacryocystitis in both acute and chronic type.

Keywords: dacryocystitis, microbiology, antibiotic susceptibility tests

\section{Introduction}

Dacryocystitis is an inflammatory condition of lacrimal sac, which is caused secondary to obstruction and blockage of normal drainage of tears that leads to secondary infection. This complication is associated with structural abnormality, infectious disorder of the eye, and traumatic injury. The main clinical symptoms include pain, redness, and swelling of lacrimal sac at medial canthus and epiphora due to inadequate drainage of tears, which in the end result in severe inflammation. Dacryocystitis occurs in both acute and chronic forms. ${ }^{1}$ The acute type is initially caused by nasolacrimal abscess, and in some instance, it is accompanied by dissemination of infection in the form of orbital cellulitis, thrombosis of the superior ophthalmic vein, and cavernous sinus. ${ }^{2-4}$ The chronic form of dacryocystitis is associated with epiphora (excessive tearing) and chronic conjunctivitis. ${ }^{5}$

The microbiological agent of dacryocystitis varies and depends on acute or chronic type. Although gram-positive bacteria are the most common cause of acute
Correspondence: Hamid Reza Ghasemi Basir

Department of Pathology, School of Medicine, Hamadan University of Medical Sciences, Pastor Crossroads, Sina Hospital, Hamadan 651674874I, Iran Tel +989188115055 Email hrgb2004@yahoo.com

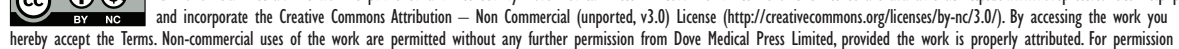
for commercial use of this work, please see paragraphs 4.2 and 5 of our Terms (https://www.dovepress.com/terms.php). 
dacryocystitis, clinicians consider gram-negative bacterium in diabetes and immunosuppressive conditions. ${ }^{1,6}$ However, several species of bacteria and fungi may be involved in the pathogenesis of chronic type. The main microorganisms include gram-positive bacteria that may be accompanied by both aerobic and anaerobic gram-negative microorganisms. ${ }^{7,8}$ Most reports have shown that fungal pathogens, such as Fusarium spp., Aspergillus spp., and Candida albicans, are major species that are usually isolated from dacryocystitis in addition to bacterial strains. ${ }^{9}$

Staphylococcus aureus, Staphylococcus haemolyticus, Streptococcus pneumoniae, and Haemophilus influenzae have been identified as common pathogens in children, and Staphylococcus epidermidis, S. aureus, S. pneumoniae, and Pseudomonas aeruginosa are the most contributing microorganisms in adults. ${ }^{10}$

The choice of antibiotic treatment for dacryocystitis depends on patient's age, disease status (acute or chronic), type of microorganism, available antibiotics and antibiotic resistance patterns in the geographic region that is related to the type of microbial resistance, the distribution of microorganisms, and the spectrum of antimicrobial agents that are used. ${ }^{9-11}$

Topical antibiotics have limited therapeutic value due to the lack of access to lacrimal system secondary to blockage in the tear drainage and also insufficient penetration into the local soft tissue. Oral antibiotics are effective in most instances. An injectable antibiotic is indicated for severe infection, especially in cellulitis. Preparation of smear and the culture of aspirated material can lead to specific antibiotic therapy, but in most instances, dacryocystitis is only treated based on clinical observations and antibiotic susceptibility tests that are not performed routinely. It should be noted that clinical findings and broad-spectrum antibiotic therapy are not effective alone as a diagnostic tool and therapeutic strategy. Therefore, in each geographic region, having information about the common microorganisms responsible for dacryocystitis is necessary as well as the pattern of antibiotic susceptibility. The aim of this study is to determinate the microbiological and clinical characteristics of dacryocystitis and investigate the antibiotic susceptibility patterns in northwest of Iran.

\section{Materials and methods}

The present research is a cross-sectional and analytical study carried out in Farshchian Hospital of Hamadan (northwest of Iran) during 2016-2017. The protocol of this study was approved by the Ethics Committee of Hamadan University of Medical Sciences with accession number: IR.UMSHA.
REC.1395.515, and written informed consent was obtained from all individuals involved. Also, parents provided written informed consent for any participant under the age of 18 years. All patients with dacryocystitis referred to the clinic of ophthalmology were selected for sampling. The only exclusion criteria were lack of patient consent for participation in the culture sampling and previous treatment with antibiotics. Nasolacrimal duct discharges were sampled by ophthalmologist under sterile conditions (without contamination of samples by skin and eyelash) and inoculated to four culture media including blood agar, eosin methylene blue, chocolate agar, and Sabouraud agar in addition to differential media to isolate and determine the bacterial and fungal strains, respectively, and then subcultured to Mueller-Hinton agar for antibiogram, using disc diffusion method with MAST antibiogram discs (made in England). The pattern of antibiotic susceptibility tests was presented at three sensitive, resistant, and intermediate levels, according to the Clinical and Laboratory Standards Institute (CLSI), 2017. Results of smear, culture, and antibiogram of patients were extracted from documents of the microbiology laboratory, and demographic and clinical data were obtained from the medical records of clinic. Acute dacryocystitis is defined as an acute inflammation of distended lacrimal sac with edema and erythema of superficial skin, while chronic dacryocystitis is specified with mucoid discharges, epiphora, congestion, and chronic conjunctivitis. Infection pattern was described separately in under 10 years' age group and the rest.

Cochran's formula for finite population was used for calculating sample size with 95\% confidence level and margin of error equal to 0.05 . Finally, the obtained data were statistically analyzed using SPSS-16 at the 5\% level of significance.

\section{Results}

A total of 129 patients with dacryocystitis were enrolled in the study, which included 46 males $(35.7 \%)$ and 83 females (64.3\%). The mean age of the participants was $43.07( \pm 29.05)$ years, with minimum of 1 month and maximum of 90 years. The most common age groups were the group under 10 years $(23.26 \%)$ and over 50 years $(46.51 \%)$ and the lowest age group was $10-30$ years (13.95\%) (Figure 1).

In this population, 50 patients had right-side involvement and 52 of them had left-side dacryocystitis. In addition, there were 27 patients with bilateral dacryocystitis. In terms of type, 44 patients $(34.1 \%)$ were encountered with acute dacryocystitis and 85 of them $(65.9 \%)$ had chronic form. In unilateral involvement, there was no significant difference 


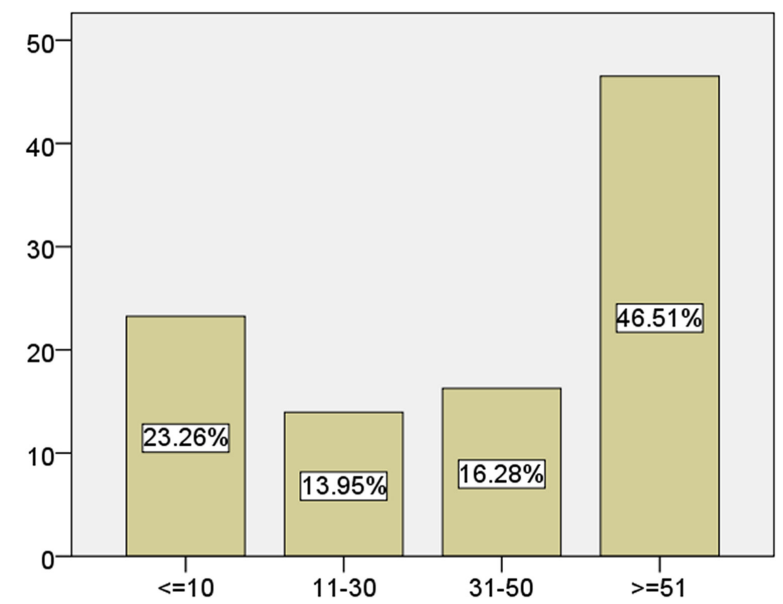

Figure I Age group of patients with dacryocystitis and percentage in population studied ( $\leq 10$ years, $\mid \mathrm{I}-30$ years, $3 \mathrm{I}-50$ years, $\geq 5 \mathrm{I}$ years).

between the incidence of acute and chronic types $(P=0.147)$. However, the frequency of chronic cases was significantly higher in patients with bilateral dacryocystitis $(P=0.027)$.

The result of culture was positive in 97 cases (75.2\%). The most common type of isolated microorganism was grampositive cocci (61.8\%). Out of 27 bacillus-shaped strains, 25 cases $(25.8 \%)$ were gram negative and $2(2 \%)$ were gram positive. Fungal species was observed in $10(10.4 \%)$ cases. Based on the morphology of cultivated microorganisms, cocci were mainly prevalent in the acute dacryocystitis (50\% of cocci isolated from acute type), while bacillus and fungus were mostly seen in the chronic type (70.37\% of bacillus and $90 \%$ of fungus isolated from chronic type).
In this study, the dominant strain in the culture media was considered as an effective microbial agent in the pathogenesis of dacryocystitis, and antibiogram was performed on this dominant strain. It was also assumed that if two strains with equal colony count were found in the medium, both of them must be introduced as causative agents of dacryocystitis, and antibiogram must be performed for each of them separately, but this situation did not occur in any of our patients. Nevertheless, in our study, polymicrobial result was obtained in 17 of 97 positive cultures and an average of 2.2 strains per culture medium was isolated from these $17.5 \%$ polymicrobial cases, but antibiogram was performed only on the dominant strain and it was reported as a microbial agent.

S. aureus, S. epidermidis, and S. pneumoniae were the most prevalent microorganisms in patients with acute dacryocystitis, while S. epidermidis, Pseudomonas spp., S. aureus, and $C$. albicans were common species in those with chronic type (Table 1).

The most sensitive antibiotics used against prevalent bacteria were ciprofloxacin (75.9\%), ceftriaxone (73.6\%), vancomycin (67.8\%), chloramphenicol (60.9\%), gentamicin (56.3\%), and erythromycin (52.9\%) (Table 2).

Also, the most common isolated microorganisms and the most sensitive antibiotics of patients with dacryocystitis have been listed in two age groups (under and above 10 years) for clinical use and empirical therapy (Table 3).

According to the chi-squared test, there was no statistically significant difference between acute and chronic types of dacryocystitis in terms of antibiogram, as the $P$-values

Table I Frequency of isolated microorganisms in patients with dacryocystitis according to the condition of the disease, along with the most sensitive antibiotics

\begin{tabular}{|l|l|l|l|l|}
\hline \multirow{2}{*}{ Strains } & \multicolumn{2}{l}{ Type of dacryocystitis } & \multirow{2}{*}{ Total } & \multirow{2}{*}{ Most sensitive antibiotics } \\
\cline { 2 - 4 } & Acute & Chronic & & Vancomycin \\
\hline Staphylococcus epidermidis & $10(25.64 \%)$ & $15(25.86 \%)$ & $25(25.8 \%)$ & Chloramphenicol \\
\hline Staphylococcus aureus & $13(33.4 \%)$ & $6(10.34 \%)$ & $19(19.6 \%)$ & Vancomycin \\
\hline Streptococcus pneumoniae & $7(17.94 \%)$ & $4(6.89 \%)$ & $\mathrm{II}(\mathrm{II.4 \% )}$ & Ciprofloxacin \\
\hline Haemophilus influenzae & $6(15.38 \%)$ & $5(8.62 \%)$ & $\mathrm{II}(1 \mathrm{I} .4 \%)$ & Ciprofloxacin \\
\hline Pseudomonas spp. & $\mathrm{I}(2.55 \%)$ & $9(15.51 \%)$ & $10(10.4 \%)$ & - \\
\hline Candida spp. & $0(0 \%)$ & $6(10.34 \%)$ & $6(6.1 \%)$ & $\begin{array}{l}\text { Erythromycin } \\
\text { Vancomycin }\end{array}$ \\
\hline Streptococcus viridans & $0(0 \%)$ & $4(6.9 \%)$ & $4(4.1 \%)$ & $\begin{array}{l}\text { Ciprofloxacin } \\
\text { Gentamicin }\end{array}$ \\
\hline Escherichia coli & & & $4(4.1 \%)$ & - \\
\hline Aspergillus & $\mathrm{I}(2.55 \%)$ & $3(5.2 \%)$ & $4(4.1 \%)$ & Vancomycin \\
\hline Diphtheroids & & $4(6.9 \%)$ & $2(2 \%)$ & Sensitive to all \\
\hline Streptococcus pyogenes & $0(0 \%)$ & $2(3.44 \%)$ & $97(100 \%)$ & \\
\hline Total & $0(0 \%)$ & $0(0 \%)$ & $58(100 \%)$ & \\
\hline
\end{tabular}


Table 2 Distribution of susceptibility and antibiotic resistance of isolated microorganisms in dacryocystitis

\begin{tabular}{|l|l|l|l|}
\hline Antibiotics & Sensitive & $\begin{array}{l}\text { Nonsensitive } \\
\text { (intermediate } \\
\text { or resistant) }\end{array}$ & Total \\
\hline Ciprofloxacin & $66(75.9 \%)$ & $21(24.1)$ & $87(100 \%)$ \\
\hline Ceftriaxone & $63(73.6 \%)$ & $23(26.4 \%)$ & $87(100 \%)$ \\
\hline Vancomycin & $59(67.8 \%)$ & $28(32.2 \%)$ & $87(100 \%)$ \\
\hline Chloramphenicol & $53(60.9 \%)$ & $34(39.1 \%)$ & $87(100 \%)$ \\
\hline Gentamicin & $49(56.3 \%)$ & $38(43.7 \%)$ & $87(100 \%)$ \\
\hline Erythromycin & $46(52.9 \%)$ & $41(47.1 \%)$ & $87(100 \%)$ \\
\hline
\end{tabular}

of difference in susceptibility test for Ceftriaxone, Ciprofloxacin, Vancomycin, Gentamicin, Chloramphenicol and Erythromycin were $0.077,0.067,0.155,0.077,0.097$, and 0.516 respectively.

\section{Discussion}

In our study, both forms of acute and chronic dacryocystitis were observed, but out of 129 patients, approximately two thirds of cases $(65.9 \%)$ had chronic dacryocystitis, with similar results in many previous studies, which represents the role of chronic structural problems in the drainage of tears. ${ }^{5,8,10,12}$

Based on previous studies, acquired nasolacrimal duct obstruction is more common in middle-aged or elderly patients. ${ }^{10,13}$ In the present study, the most common age group was over 50 years old, which accounted for $46.51 \%$ of patients and $62.8 \%$ of the subjects were over 30 years old; these suggest that the etiology of disease is acquired over time.

We investigated the sex ratio that reflects the superiority of females than males (64.3\%, which was 1.8 times higher than men). Similarly, higher percentages of acute and chronic dacryocystitis have been reported in women than in men, in previous studies. ${ }^{9,10,14,15}$ Perhaps the smaller diameter of the nasolacrimal duct in women can explain the cause. ${ }^{16}$

In terms of the side of the conflict, there was no difference between the left and right sides in our study. It should

Table 3 The most common isolated microorganisms and the most sensitive antibiotics of patients with dacryocystitis according to the age groups

\begin{tabular}{|l|l|l|}
\hline Age group & $\begin{array}{l}\text { Most common isolated } \\
\text { microorganisms }\end{array}$ & $\begin{array}{l}\text { Most sensitive } \\
\text { antibiotics }\end{array}$ \\
\hline$\leq 10$ years & $\begin{array}{l}\text { Pseudomonas spp. } \\
\text { Haemophilus influenzae }\end{array}$ & $\begin{array}{l}\text { Ciprofloxacin } \\
\text { Vancomycin }\end{array}$ \\
\hline$>10$ years & $\begin{array}{l}\text { Staphylococcus epidermidis } \\
\text { Staphylococcus aureus }\end{array}$ & $\begin{array}{l}\text { Ciprofloxacin } \\
\text { Vancomycin }\end{array}$ \\
\hline
\end{tabular}

be noted that about $21 \%$ of subjects had dacryocystitis in both sides, and in most cases, it was unilateral. This suggests important role of structural bugs that lead to bacterial colonization because the disease is mostly limited to the side that its drainage is damaged.

Occurrence of dacryocystitis and its severity are dependent on the geography of the region and the type of microbial agents. ${ }^{9}$ During the past 50 years, the microbiological agents of the dacryocystitis have changed; for example, the contribution of S. pneumoniae, which in 1930s was the most frequent species of dacryocystitis, was reduced to less than frequency of Streptococcus epidermidis. ${ }^{1}$ Microbial diversity of our study was widespread, with different types of bacteria with cocci and bacilli forms including gram-positive and gramnegative species and two fungal species isolated from positive culture, and this variation was consistent with previous studies focusing on microbiological analysis of dacryocystitis., ${ }^{9,12,13}$

In our study on 129 cases, the results of the culture were negative in $24.8 \%$, which indicates that there is no growing aerobic factor in one quarter of the patients and suggests the probability of anaerobic agents as an etiologic factor. Although we had signified previous treatment as an exclusion criterion, the cases treated with hidden antibiotics and unknown medications should be considered as possible causes of negative culture results.

The general trend of previous studies including Chaudhry et al (2005), Bharathi et al (2008), Huber-Spitzy et al (1992), Mills et al (2007), Ali et al (2013), and Assefa et al (2015) indicates that gram-positive organisms dominate in both acute and chronic dacryocystitis, and the most common being staphylococcal species. ${ }^{1,6,8,9,12,14}$ The prevalence of gram-positive bacteria in dacryocystitis has been reported in Finland (62\%), Australia (54.4\%), Saudi Arabia (79.1\%), the USA (68.8\%), and in a previous study conducted in Iran $(68.8 \%)^{7}{ }^{72,17-19}$ In our study, most of the isolated bacteria were gram positive $(63.8 \%)$ and more accurately, grampositive cocci (61.8\%) followed by gram-negative bacilli (25.8\%) and fungus species (10.4\%), respectively. Also, $45.4 \%$ of isolated strains were staphylococcal species.

In the current study, the most isolated bacteria in children under the age of 10 years were Pseudomonas and $H$. influenzae, while in subjects older than 10 years, $S$. epidermidis and $S$. aureus were the most isolated bacteria. In previous studies, different amounts of gram-negative bacteria such as $H$. influenzae, $P$. aeruginosa, and Escherichia coli have been isolated; 9.7\% Pseudomonas, 6.5\% H. influenzae, and 6.5\% Enterobacteriaceae species have been reported in the study by Assefa et al (2015), and similar 
results have been identified in other studies including 9.9\% H. influenzae in the study by Kebede et al (2010), 15.2\% Pseudomonas in the study by Pornpanich et al (2016), seven species of Pseudomonas in the study by Brook and Frazier (1998), and $11.7 \%$ E. coli in the study by Huber-Spitzy et al (1992). ${ }^{1,9,20-22}$ In our study, 25.9\% (one quarter of cases) of infections were associated with gram-negative bacteria, including $H$. influenzae, Pseudomonas, and E. coli.

In our study, the prevalence of organisms responsible for acute and chronic dacryocystitis was different. Despite the fact that cocci were the most isolated bacteria from acute $(76.9 \%)$ and chronic (51.7\%) type of disease, most isolates from 39 cases of acute dacryocystitis included S. aureus (33.3\%), Staphylococcus epidermis (25.6\%), and S. pneumoniae (17.9\%) and of the 58 cases of chronic lesion, the most isolated organisms were S. epidermis (25.8\%), Pseudomonas (15.5\%), C. albicans (10.3\%), and S. aureus (10.3\%). Interestingly, while Pseudomonas and fungal infections were reported as $2.5 \%$ in acute dacryocystitis, in chronic lesions fungal infections and Pseudomonas were formed in $32.7 \%$ of infections. Also, among gram-positive cocci, $S$. aureus is the most common in acute lesions and $S$. epidermidis in chronic types. The same frequency is observed in the study by Eshraghi et al in Iran, just like our study. ${ }^{10}$ In this study, gram-negative bacteria were found to be more prevalent in chronic dacryocystitis that was in contrary to the study by Eshraghi et al in Iran and the study by Hartikainen et al in Finland. ${ }^{10,19}$

In general, the causes of this bacterial diversity in various studies can be due to the number of patients in different studies, the geographical differences in regional pathogens, the difference in the social level of patients, the availability of ophthalmology care, and the awareness of individuals to public health.

In dacryocystitis, treatment of obstruction in the nasolacrimal duct is a surgical intervention. Despite the surgical procedures, in the absence of systemic antibiotics, the likelihood of soft tissue infection is fivefold, ${ }^{20}$ which indicates the role of antibiotics in the treatment of dacryocystitis. In addition, the importance of antibiotic resistance is a challenge that affects the management of dacryocystitis. In the study by Assefa et al (2015), ceftriaxone (95.3\%), erythromycin (84.2\%), nalidixic acid (87.1\%), and gentamicin (83.3\%) were the most susceptible antibiotics. ${ }^{9}$ In the study by Kebede et al, chloramphenicol (82.4\%), gentamicin (79.1\%), erythromycin $(68.1 \%)$, and tetracycline $(61.5 \%)$ had the highest effects in antibiogram. ${ }^{20}$

In this study, among the various strains, the most effective antibiotics were ciprofloxacin $(75.9 \%)$, followed by ceftriaxone (73.6\%), vancomycin $(67.8 \%)$, chloramphenicol $(60.9 \%)$, gentamicin $(56.3 \%)$, and erythromycin $(52.9 \%)$. It should be noted that although ciprofloxacin was the most common susceptible antibiotic to isolated bacteria, but the greatest effect was on gram-negative microorganisms such as $H$. influenzae, Pseudomonas, and E. coli, which were not common pathogens of dacryocystitis. Although $S$. aureus, S. Epidermidis, and S. pneumoniae (the most isolated bacteria from acute and chronic dacryocystitis) were most susceptible to vancomycin and chloramphenicol, but it should be noted that because antibiotic resistance to chloramphenicol and vancomycin has been reported between $32 \%$ and $39 \%$, determination of the bacterial species and antibiogram seems to be important in patients with dacryocystitis. According to our findings, after $S$. epidermidis, the most isolated bacteria in chronic dacryocystitis is Pseudomonas. Considering that Pseudomonas has the highest sensitivity to ciprofloxacin, it seems that in addition to vancomycin, ciprofloxacin is also important in the management of chronic disease. In addition, in children under the age of 10 years, Pseudomonas and $H$. influenzae were the most common pathogens with greatest susceptibility to ciprofloxacin and vancomycin.

The difference among studies indicates that there are obvious variations in antibiotic susceptibility pattern in the geographic areas due to the regional pathogens.

\section{Conclusion}

Available studies show that microorganisms isolated from patients with dacryocystitis are various based on their regional distribution, prevalence, and antibiotic susceptibility patterns in different geographic areas. The present study is useful for determining the appropriate antibiotic for systemic treatment of dacryocystitis in our region. According to our findings, ciprofloxacin and vancomycin are the most sensitive antibiotics against the most common isolated microorganisms in both age groups (under and above 10 years). In order to use appropriate antibiotics, each region should have sufficient periodic information about the various pathogens involved in dacryocystitis and their antibiotic susceptibility to achieve effective empirical treatment. So, by managing the order of antibiotics, we can control antibiotic resistance. The use of a broader spectrum of antibiotics and anaerobic culture media can be considered in future studies.

\section{Acknowledgments}

The authors would like to thank the personnel of laboratory in Sina Hospital for their contributions in this study. Moreover, the study was supported by the Vice Chancellor of Research 
and Technology, Hamadan University of Medical Sciences, Hamadan, Iran.

\section{Disclosure}

The authors report no conflicts of interest in this work.

\section{References}

1. Huber-Spitzy V, Steinkogler FJ, Huber E, Arocker-Mettinger E, Schiffbänker M. Acquired dacryocystitis: microbiology and conservative therapy. Acta Ophthalmol. 1992;70(6):745-749.

2. Ataullah S, Sloan B. Acute dacryocystitis presenting as an orbital abscess. Clin Exp Ophthalmol. 2002;30(1):44-46.

3. Janssen AG, Mansour K, Bos JJ, Manoliu RA, Castelijns JA. Abscess of the lacrimal sac due to chronic or subacute dacryocystitis: treatment with temporary stent placement in the nasolacrimal duct. Radiology. 2000;215(1):300-304.

4. Maheshwari R, Maheshwari S, Shah T. Acute dacryocystitis causing orbital cellulitis and abscess. Orbit. 2009;28(2-3):196-199.

5. Pradeep AV, Patil SS, Koti SV, Kumar A, Garag SS, Hegde JS. Clinico-bacteriological study of chronic dacryocystitis cases in northern Karnataka, India. J Clin Diagn Res. 2013;7(11):2502-2504.

6. Chaudhry IA, Shamsi FA, Al-Rashed W. Bacteriology of chronic dacryocystitis in a tertiary eye care center. Ophthalmic Plast Reconstr Surg. 2005;21(3):207-210.

7. Sainju R, Franzco AA, Shrestha MK, Ruit S. Microbiology of dacryocystitis among adults population in southern Australia. Nepal Med Coll J. 2005; 7(1):18-20.

8. Bharathi MJ, Ramakrishnan R, Maneksha V, Shivakumar C, Nithya V, Mittal S. Comparative bacteriology of acute and chronic dacryocystitis. Eye. 2008;22(7):953-960

9. Assefa Y, Moges F, Endris M, et al. Bacteriological profile and drug susceptibility patterns in dacryocystitis patients attending Gondar University Teaching Hospital, Northwest Ethiopia. BMC Ophthalmol. 2015;15(1):1-8.

10. Eshraghi B, Abdi P, Akbari M, Fard MA. Microbiologic spectrum of acute and chronic dacryocystitis. Int J Ophthalmol. 2014;7(5): $864-867$.
11. Coden DJ, Hornblass A, Haas BD. Clinical bacteriology of dacryocystitis in adults. Ophthalmic Plast Reconstr Surg. 1993;9(2):125-131.

12. Mills DM, Bodman MG, Meyer DR, Morton AD; ASOPRS Dacryocystitis Study Group. The microbiologic spectrum of dacryocystitis: a national study of acute versus chronic infection. Ophthalmic Plast Reconstr Surg. 2007;23(4):302-306.

13. Sun X, Liang Q, Luo S, Wang Z, Li R, Jin X. Microbiological analysis of chronic dacryocystitis. Ophthalmic Physiol Opt. 2005;25(3): 261-263.

14. Ali MJ, Joshi SD, Naik MN, Honavar SG. Clinical profile and management outcome of acute dacryocystitis: two decades of experience in a tertiary eye care center. Semin Ophthalmol. 2015;30(2):118-123.

15. Madhusudhan, Muslikan Y, Ismail N, Hussein A. Microbiological aetiology of acute dacryocystitis in hospital University Sains Malaysia, Kelantan Malaysia. J Acute Dis. 2012;1(1):31-34.

16. Mccormick A, Sloan B. The diameter of the nasolacrimal canal measured by computed tomography: gender and racial differences. Clin Exp Ophthalmol. 2009;37(4):357-361.

17. Razavi ME, Ansari-Astaneh MR, Farzadnia M, Rahmaniyan H, Moghiman T. Bacteriological evaluation of adult dacryocystitis in Iran. Orbit. 2010;29(5):286-290.

18. Begum NN, Al-Khattaf AS, Al-Mansouri SM, Yeboah EA, Kambal AM. A study of bacterial isolates from corneal specimens and their antibiotic resistance profile. Saudi Med J. 2006;27(1):41-45.

19. Hartikainen J, Lehtonen OP, Saari KM. Bacteriology of lacrimal duct obstruction in adults. Br J Ophthalmol. 1997;81(1):37-40.

20. Kebede A, Adamu Y, Bejiga A. Bacteriological study of dacryocystitis among patients attending in Menelik II Hospital, Addis Ababa, Ethiopia. Ethiop Med J. 2010;48(1):29-33.

21. Pornpanich K, Luemsamran P, Leelaporn A, et al. Microbiology of primary acquired nasolacrimal duct obstruction: simple epiphora, acute dacryocystitis, and chronic dacryocystitis. Clin Ophthalmol. 2016; 10:337-342.

22. Brook I, Frazier EH. Aerobic and anaerobic microbiology of dacryocystitis. Am J Ophthalmol. 1998;125(4):552-554.
Clinical Ophthalmology

\section{Publish your work in this journal}

Clinical Ophthalmology is an international, peer-reviewed journal covering all subspecialties within ophthalmology. Key topics include: Optometry; Visual science; Pharmacology and drug therapy in eye diseases; Basic Sciences; Primary and Secondary eye care; Patient Safety and Quality of Care Improvements. This journal is indexed on Submit your manuscript here: http://www.dovepress.com/clinical-ophthalmology-journal

\section{Dovepress}

PubMed Central and CAS, and is the official journal of The Society of Clinical Ophthalmology (SCO). The manuscript management system is completely online and includes a very quick and fair peer-review system, which is all easy to use. Visit http://www.dovepress.com/ testimonials.php to read real quotes from published authors. 